\title{
The Use of Histochrome in the Complex Treatment of the Patients with Acute Coronary Syndrome with ST Segment Depression Diagnosed on ECG
}

\author{
Zulfia Kim $^{4,5}$, Farid Ishkineev ${ }^{2}$, Elvira Khusnullina ${ }^{3} \&$ Raushania Gaifullina $^{1}$ \\ ${ }^{1}$ Institute of Fundamental Medicine and Biology of Kazan Federal University, Kazan, Russia \\ ${ }^{2}$ Medical unit of Russian Federation Ministry of the Interior in the Republic of Tatarstan, Kazan, Russia \\ ${ }^{3}$ Science and Research Agency, Kazan Federal University, Kazan, Russia \\ ${ }^{4}$ Department of Internal Diseases \#2 of Kazan State Medical University, Kazan, Russia \\ ${ }^{5}$ Emergency care hospital \#1, Kazan, Russia \\ Correspondance: Raushania Gaifullina, Institute of Fundamental Medicine and Biology, 420008, Kazan, \\ Republic of Tatarstan, Russian Federation. Tel: 7-843-233-78-41. E-mail: raushania13@rambler.ru
}

Received: September 20, 2014

doi:10.5539/mas.v9n1p161
Accepted: October 2, 2014 Online Published: December 10, 2014

URL: http://dx.doi.org/10.5539/mas.v9n1p161

\begin{abstract}
The article presents high clinical efficiency and the absence of side effects of the use of histochrome in the complex treatment of the patients with acute coronary syndrome with ST segment depression diagnosed on ECG.
\end{abstract}

Keywords: acute coronary syndrome, ischemic heart disease, histochrome

\section{Introduction}

Every year cardio-vascular disease is diagnosed in up to 20 million people in Russia and the fatality level in cardiovascular cases is still very high.

Acute coronary syndrome with non-ST segment elevation is one of the reasons of destabilization of ischemic heart disease (IHD) progress. Electrocardiogram (ECG) taken at the moment of attack behind the breast bone of such patients can demonstrate ST-segment depression, which indicates ischemia or progressing myocardial infarction. Our records indicate that similar results are registered on ECG at $10 \%$ of patients hospitalized to the acute unit, and it can be itself estimated as the predictor of poor clinical outcome. So, ECG diagnosis of ST segment depression at the patent cardiology of acute coronary syndrome increases the risk of acute myocardial infarction at 4,49 $(\mathrm{p}=0,00)$ times, and relational risk of lethal outcome at 7,78 (p=0,01) times (Latfullin, 2010).

As is known, patients with acute coronary syndrome and ST segment depression suffer from multiple lesions of distal coronary artery, progress of ischemic myocardial necrosis and appearance of hibernating cardiomyocyte. Taking in consideration that main energetic substrates used by myocardium are carbohydrates, lipids, and ketone bodies aerobic type of catabolism would be the most effective in case of proper vascular supply and oxygen delivery, and economic anaerobic glycolysis and $\beta$-aciditification of free fatty acids in case of ischemia (Opie, 1991). In case of ischemia and high concentration of free fatty acids there is increasing oxygen demand of myocardium which is not followed by the increase of mechanical (Opie, 1991, Stanley, 1997, Schamroth, 1975, Richmond, 1980). Besides that, in case of predominant $\beta$-aciditification of free fatty acids myocardial contractile function decreases, cellular glucose delivery is getting blocked, concentration of cyclic AMP increases, toxic products of fatty acids decomposition accumulate and they might destroy cellular membranes and may lead to onset of arrhythmia.

The aforesaid determinates the necessity of use of medication with positive effect at energetic metabolism of cardiocytes in treatment of patients suffering from acute coronary syndrome with ST segment depression.

Among Russian antioxidant medicaments, "Histochrome" (pentahydroxiethylnaphthoquinone) elaborated by Pacific Institute of Bioorganic Chemistry (Far Eastern unit of Russian Academy of Science, Vladivostok) can be 
mentioned. It is known that the medicament stabilizes cellular membranes, interoperates with a reactive oxygen species, reduces the number of lipid peroxygenation debris.

Huge exprience of the use of histochrome in ophthalmology and cardiology has been gained for more than 20 years of its existence. Today, high cardio-protective characteristics of histochrome for patients with IHD (acute myocardial infarction, unstable cardiac angina, chronic ischemic heart disease) is proved by experimental and cclinical researches. According to Zakirova A. and co-authors the main mechanisms for positive cardiohaemodynamic effects of histochrome are complimentary antioxidant and disaggregational medical claims (Zakirova, 1997).

Researches explain the additional concentration of histochrome (in 2-6 hours) after its decrease by enterohipatic recirculation of histochrome, i.e. biliary excretion aTd repeated intestinal absorption (Zakirova, 1997), repair of major metabolite (tetraketone) to original histochrome with such bioactive compounds as glutathione (GSH), cysteine, and ascorbic acid Mischenko, 1991).

Histochrome is supposed to storage on fatty tissue what provides prolonged period of medicament elimination and remaining protective effect in case of acute myocardial infarction for more than 1 day (Zakirova, 1997). There is evidence demonstrating that acute myocardial infarction volume decreases to $54 \%$ in 12 hours and to $18,4 \%$ in 24 hours after single infusion of histochrome (Zakirova, 1997).

Besides that, in case of acute myocardial infarction the use of histochrome prevent aftereffect of illness, including life-threatening, thus increasing survival rate. The medicament positively impacts on coronary hemodynamic and myocardial contractility on the model "ischemia-reperfusion" (Zakirova, 1997, Novikov, 1996). So, decrease of reperfusion heart rhythm disorder quantity and length of their existence in reperfusion period (Markov, 1999). Histochrome infusion after acute myocardial infarction facilitate the increase of ejection fraction, decrease the risk of left ventricular failure, and restraint its development after effective thrombolytic therapy.

According to the clinical experience of Lasukova T. and co-authors, it's recommended to use histochrome in the complex of preoperational preparation during cardiac artery bypass graft to ischemic heart disease patients (Lasukova, 1997).

High antioxidant activity, effectiveness of use of the medicament on different types of ischemic heart disease, and the lack of data of its use for patients with acute coronary syndrome with ST segment depression, have determined the necessity of our research.

The aim of the research: Evaluation of clinical effectiveness and safety of histochromee at patients with acute coronary syndrome with ST segment depression demonstrated on ECG during anginal attack.

\section{Materials and Methods}

59 patients with acute coronary syndrome, who were hospitalized to cardiology unit \#1 of Kazan Emergency care hospital \#1, were examined during the research. At all the patients anginal attack was accompanied by horizontal or oblique increasing ST-segment decrease by $1-7 \mathrm{~mm}$ in 0,08 seconds after J point with the heart rate of 50-120 beats per minute. There are $21 \mathrm{men}(35,59 \%)$ and 38 women $(64,41 \%)$ in the group, their average age is $58,48 \pm 3,02$ years. Acute coronary syndrome was transformed to acute myocardial infarction at 31 patients, among them 11 - with Q wave, and 20 - without Q wave. 26 people $(44,06 \%)$ had myocardial infarction in anamnesis (postinfarction cardiosclerosis); 11 patients $(18,64 \%)$ had repeated myocardial infarction. 28 patients $(47,45 \%)$ were diagnosed with effort angina of III-IV functional class by the end of acute coronary syndrome.

54 patients $(91,52 \%)$ has suffered from arterial hypertension. The following figures were registered at patients upon entering the hospital, such as: arterial tension of 140-159/90 - 99 mm of mercury was registered at 12 people (20,34\%), $160-179 / 100-109 \mathrm{~mm}$ of mercury - at 29 people $(49,15 \%)$, and $\geq 180 / \geq 110 \mathrm{~mm}$ of mercury - at 18 people $(30,51 \%)$.

Electrocardiographic effects of left ventricular hypertrophy was diagnosed at 11 patients with ischemic heart disease $(18,6 \%)$, and in 8 cases $(13,6 \%)$ - in combination with arterial hypertension.

21 person $(35,6 \%)$ had evidences of the heart failure of I-IV functional classes according to NYHA classification.

All the patients got standard therapy of acute coronary syndrome without ST segment rise, this included the following: anticlotting agents, disaggregants, b- adrenoreceptor blocking agents, nitrates, ACE inhibitor, statins; and diuretic or calcium antagonist if necessary. 
Patients were randomized into 2 groups, as follows:

$1^{\text {st }}$ group - the main group (27 people) consists of patients who got histochrome infusions in the dose of $100 \mathrm{mg}$ once a day in addition to the main therapy during the first 3 days of hospitalization.

$2^{\text {nd }}$ group - comparative group (32 people) consists of patients with ischemic heart disease who are getting standard treatment.

All the patients got standard 12-lead ECG registered, echo-cardiography $\left(\mathrm{ON} 2^{\text {nd }}-3^{\text {d }}\right.$, and $10^{\text {th }}$ day of hospitalization), 24-hour Holter ECG monitoring, estimated hemodynamic parameters (arterial tension, heart rate). They also got clinical and biochemical blood values diagnosed on $1^{\text {st }}$ and $10^{\text {th }}$ day of hospitalization.

Besides the listed examinations, dynamics of late ventriclar potentials expression was analysed by the use of the recording method using ECG without temporal and spatial averaging of cardio signal. ECG registration and analysis was held on computer cardiograph [14] by entering the hospital, and at $3^{\mathrm{d}}, 7^{\text {th }}, 10^{\text {th }}$ day of hospitalization. The following criteria were used to late ventriclar potensials analysis (Stepura, 1997):

1) QRS complex duration $>114$ msec;

2) complex terminal note $<40$ micro Volt;

3) root-meansquare of tention during the last 40 msecs of QRS complex $<25$ micro Volt.

Late ventriclar potential was diagnosed in case of the presence of 2-3 mentioned "classic" criteria.

The questionnaire, formulated by members of internal diseases department \#2 of Kazan State Medical University, was used to evaluate subjective condition of patients.

Statistical analysis of information was organized with the use of standard programs package STATISTICA.

\section{Results and Discussion}

ECG of 25 patients $(42,37 \%)$ demonstrated different rhythm disorders, among them supraventricular extrasystole was registered at 4patients $(6,78 \%)$, ventricular premature beats of the I grade (according to B. Lown, N. Wolff) was registered at 3 patients $(5,08 \%)$, at the II grade - at 8 patients $(13,56 \%)$, permanent was registered at 6 patients $(10,16 \%)$, and paroxysmal arterial fibrillation - at 4 patients $(6,78 \%)$.

Conduction defects are registered at 7 patients $(11,86 \%)$, as follows: left anterior fascicular block in 5 cases $(8,47 \%)$ and complete right bundle branch block in 2 cases $(3,39 \%)$.

Two groups of patients did not significantly differ by their age, sex, and cardio-vascular risk (table 1).

Table 1. Clinical-demographic characteristics of groups of patients involved in the research

\begin{tabular}{|c|c|c|c|c|c|c|}
\hline Parameters & $\begin{array}{c}\text { Both } \\
\text { groups }\end{array}$ & $(\%)$ & $\begin{array}{l}\text { Patients taking } \\
\text { Histochromee }\end{array}$ & $(\%)$ & $\begin{array}{c}\text { Comparative } \\
\text { group patients }\end{array}$ & $(\%)$ \\
\hline \multicolumn{7}{|c|}{ Number of patients with ischemic heart disease } \\
\hline & 59 & $(100 \%)$ & 27 & $(100 \%)$ & 32 & $(100 \%)$ \\
\hline Age & \multicolumn{2}{|c|}{$58,4 \pm 3,02$} & \multicolumn{2}{|c|}{$60,8 \pm 1,06$} & \multicolumn{2}{|c|}{$56,4 \pm 4,03$} \\
\hline \multicolumn{7}{|c|}{ Hemodynamics parameters } \\
\hline Heart rate & \multicolumn{2}{|c|}{$86,4 \pm 2,08$} & \multicolumn{2}{|c|}{$78,6 \pm 3,07$} & \multicolumn{2}{|c|}{$93,2 \pm 1,06$} \\
\hline $\begin{array}{l}\text { Systolic blood } \\
\text { pressure }\end{array}$ & \multicolumn{2}{|c|}{$158,19 \pm 5,48$} & \multicolumn{2}{|c|}{$163,09 \pm 6,09$} & \multicolumn{2}{|c|}{$152,13 \pm 4,15$} \\
\hline $\begin{array}{l}\text { Diastolic blood } \\
\text { pressure }\end{array}$ & \multicolumn{2}{|c|}{$97,73 \pm 3,37$} & \multicolumn{2}{|c|}{$100,03 \pm 2,22$} & \multicolumn{2}{|c|}{$86,83 \pm 4,28$} \\
\hline Women & 38 & $(64,41 \%)$ & 18 & $(66,66 \%)$ & 20 & $(62,5 \%)$ \\
\hline Men & 21 & $(35,59 \%)$ & 9 & $(33,33 \%)$ & 12 & $(37,5 \%)$ \\
\hline $\begin{array}{c}\text { Acute } \\
\text { myocardial } \\
\text { infarction }\end{array}$ & 31 & $(52,54 \%)$ & 13 & $(48,14 \%)$ & 18 & $(56,25 \%)$ \\
\hline $\begin{array}{l}\text { Postinfarction } \\
\text { cardiosclerosis }\end{array}$ & 26 & $(44,06 \%)$ & 12 & $(44,44 \%)$ & 14 & $(43,75)$ \\
\hline $\begin{array}{l}\text { Repeated acute } \\
\text { myocardial } \\
\text { infarction }\end{array}$ & 11 & $(18,64 \%)$ & 5 & $(18,51 \%)$ & 6 & $(18,75 \%)$ \\
\hline
\end{tabular}




\begin{tabular}{lcccccc}
\hline $\begin{array}{l}\text { Effort angina of } \\
\text { III-IV } \\
\text { functional class }\end{array}$ & 28 & $(47,45 \%)$ & 14 & $(51,85 \%)$ & 14 & $(43,75 \%)$ \\
$\begin{array}{l}\text { Essential } \\
\text { hypertension of }\end{array}$ & 54 & $(91,52 \%)$ & 23 & $(85,18 \%)$ & 31 & $(96,87 \%)$ \\
$\begin{array}{l}2-3 \text { degree } \\
\begin{array}{l}\text { Rhythm } \\
\text { disturbance }\end{array}\end{array}$ & 25 & $(42,37 \%)$ & 11 & $(40,74 \%)$ & 14 & $(43,75 \%)$ \\
$\begin{array}{l}\text { Right and left } \\
\text { bundle branch } \\
\text { conduction } \\
\text { defect }\end{array}$ & 7 & $(11,86 \%)$ & 3 & $(11,11 \%)$ & 4 & $(12,5 \%)$ \\
\hline
\end{tabular}

Average arterial tension rate before treatment at the $1^{\text {st }}$ group of patients (27 people) demonstrated systolic arterial tension of $163,09 \pm 6,09$ and diastolic arterial tension of $97,73 \pm 3,37 \mathrm{~mm}$ of mercury. As for the comparative group ( 32 people), the rates were the following: systolic arterial tension of $152,13 \pm 4,15$ and diastolic arterial tension of $86,83 \pm 4,28 \mathrm{~mm}$ of mercury.

Significant decrease of arterial pressure parameters was registered at both groups (59 people) against the course of antihypertensive therapy, as follows: systolic arterial tension of 122,06 $\pm 3,23$ and diastolic arterial tension of $74,18 \pm 2,18 \mathrm{~mm}$ of mercury (Figure 1). However, it is notable that positive effect of histochrome has intensified hypotensive effect of the main medicaments which can be proved by faster achieve of the aimed indicators of arterial tension of the $1^{\text {st }}$ group patients. Apart from positive dynamics of arterial pressure, chronotropic effect of histochrome was also registered in the way of heart-rate fall $86,4 \pm 2,08$ till $72,34 \pm 5,62$ beats per minute (Figure 2).

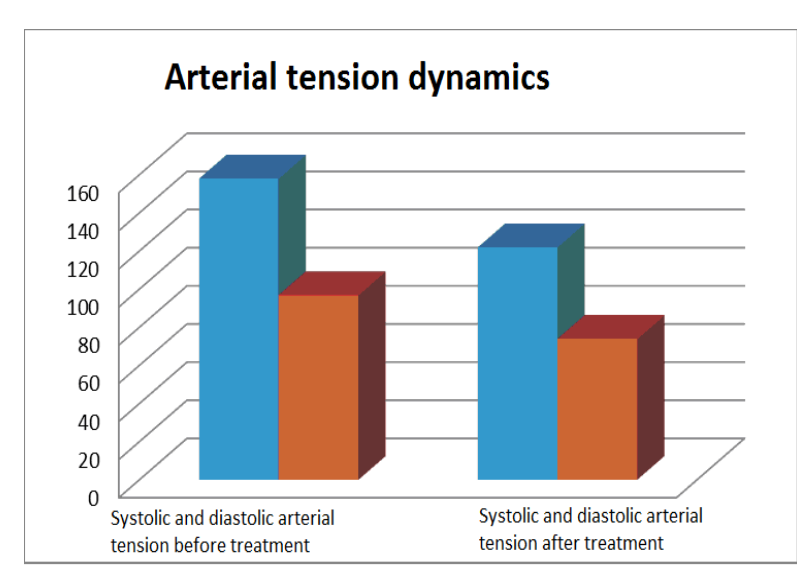

Figure 1.

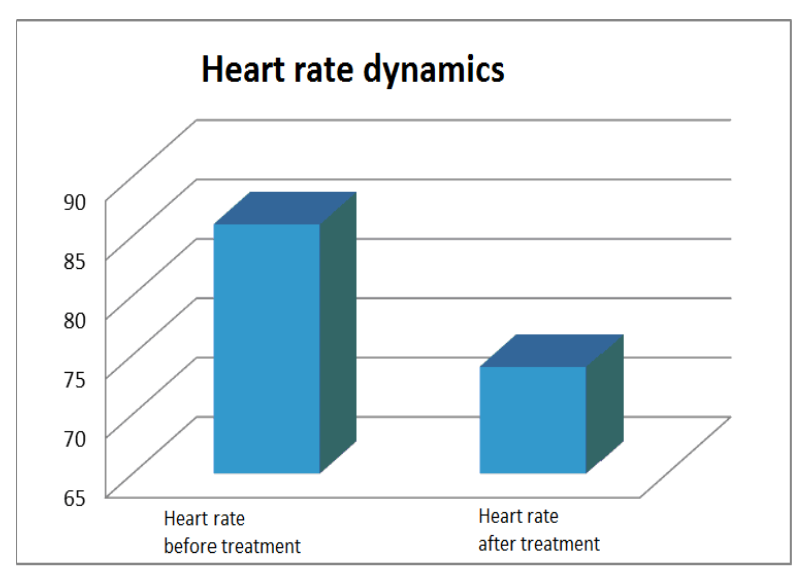

Figure 2.

Positive influence of the medicament on cardio-vascular system was observed by the improvement of hemodynamic. So, heart rate decreased on $16,3 \%$ and reached intended use after three uses of histochrome, while in control group it has decreased only on $6,8 \%$.

According to high resolution ECG data, late ventriclar potentials was registered at 18 patients $(30,51 \%)$, among them 8 patients $(29,63 \%)$ from the main group and 10 patients $(31,25 \%)$ from the comparative group. During the process of the group division according to the rate of myocardium damage it was found that late ventriclar potentials were more frequently registered at patients who already had myocardial infarction (57,69\%) and acute myocardial infarction with Q wave (54,54\%). Regarding other cases, late ventriclar potentials were registered in $40 \%$ of cases with acute myocardial infarction without $Q$ wave, in 36,36 \% of left ventricular hypertrophy cases, and in $52 \%$ of heart beat disorder cases. The frequency of registration of late ventriclar potentials at patients with different variants of acute myocardial infarction (AMI), postinfarction cardiosclerosis (PICS), left ventricular hypertrophy $(\mathrm{LVH})$, heart beat disorder (HBD) is presented in the $2^{\text {nd }}$ table. 
Table 2. Some of the clinical characteristics of patients of the main and control groups

\begin{tabular}{lllll}
\hline & \multicolumn{2}{l}{ Examined group } & \multicolumn{2}{l}{ Control group } \\
Illness classes & $\begin{array}{l}\text { Total } \\
\text { number }\end{array}$ & $\begin{array}{l}\text { Late ventriclar potentials } \\
\text { (absolute number., \%) }\end{array}$ & $\begin{array}{l}\text { Total } \\
\text { number }\end{array}$ & $\begin{array}{l}\text { Late ventriclar potentials } \\
\text { (absolute number., \%) }\end{array}$ \\
\hline $\begin{array}{l}\text { AMI without } \\
\text { Q wave }\end{array}$ & 6 & $2(33,3)$ & 14 & $6(42,9)$ \\
$\begin{array}{l}\text { AMI with Q } \\
\text { wave }\end{array}$ & 4 & $2(50)$ & 7 & $4(57,1)$ \\
PICS & 11 & $6(54,5)$ & 15 & $9(60)$ \\
LVH & 5 & $2(40)$ & 6 & $2(33,3)$ \\
HBD & 11 & $6(54,5)$ & 14 & $7(50)$ \\
\hline
\end{tabular}

As is known, the frequency of late ventriclar potential registration is dynamic and it can decrease along with recovery of electrophysiological homogeneity of myocardium. Late ventriclar potentials was registered at 14 patients $(23,72 \%)$ by hospitalization, and at four more patients only on the third day of hospitalization. Consequently, initially late ventriclar potential was registered at 18 patients $(30,51 \%)$ on $1-3$ days. Together with medicament treatment and state stabilization the frequency of late ventriclar potential registrations reduced up to $22,03 \%$ (13 people) by the $7^{\text {th }}$ day, and up to $15,25 \%$ ( 9 patients) by the $10^{\text {th }}$ day of hospitalization. Changes in the late ventriclar potential registration frequency of both groups together with therapy is presented on the Figure 3 .

It stands to mention, that initial frequency of late ventriclar potential registrations (on 1-3 days) match in two groups $(29,63 \%$ and $31,25 \%)$. Together with the main therapy the amount of the patients with slow fragment ventricle activity in the histochrome group significantly differs from the comparative group, so it is $18,52 \%$ against $25,0 \%$ on the $7^{\text {th }}$ day, and $11,11 \%$ against $18,75 \%$ on $10^{\text {th }}$ day of hospitalization.

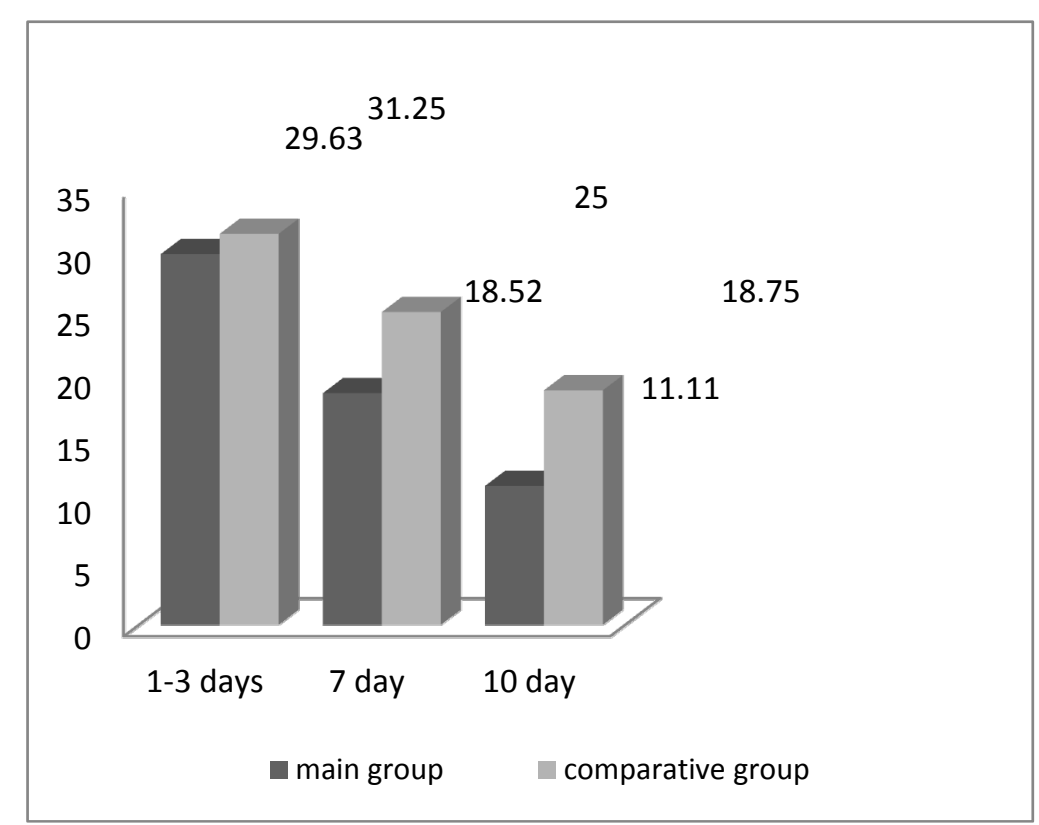

Figure 3. Dynamics of late ventriclar potential at patients with acute coronary syndrome with ST-segment depression with the use of histochrome among with standard therapy

Heart beat disorder wasn't registered at the patients who had extrasystole against the use of histrchrome. The number of painful and unpainful ischemic attacs decreased at 72,8\% (in 1st group) and at 45,6\% (in 2nd group). 
It is notable that after histochrome infusion therapy there has been positive dynamics of Holter monitoring parameters indicating improvement of coronary circulation and ischemic episodes expression, while there were no significant improvement of these parameters in the comparative group. Besides that, total running time of ischemic attacs decreased on $59 \%$, $\Sigma$ ST volume decreased on $67,6 \%$ (table 3), what was followed by decrease of the number of taken nitroglycerin pills on $62,6 \%$. The results of subjective evaluation of state of health are demonstrated in the table 4 .

Table 3. Parameters of 24-hour ECG monitoring of the patients of both groups

\begin{tabular}{|c|c|c|c|c|}
\hline $\begin{array}{l}\text { Holter monitoring para } \\
\text { Parameter }\end{array}$ & $\mathrm{rs}(\mathrm{M} \pm \mathrm{m})$ & $\begin{array}{l}\text { Group } 1(\mathrm{~N}=27) \\
\text { Group } 2(\mathrm{~N}=32)\end{array}$ & Initially & During the treatment \\
\hline \multirow{8}{*}{$\begin{array}{l}\mathrm{ST} \text { shft integral, } \mathrm{mV} \\
/ \mathrm{min} \\
\text { Number of ischemic } \\
\text { episodes per day }\end{array}$} & \multirow{4}{*}{ total } & $1 \mathrm{st}$ & $56,2 \pm 1,4$ & $32,2 \pm 2,2$ \\
\hline & & 2nd & $66,4 \pm 2,3$ & $58,4 \pm 3,2$ \\
\hline & & $1 \mathrm{st}$ & $8,2 \pm 1,3$ & $5,9 \pm 1,2$ \\
\hline & & 2nd & $8,5 \pm 1,3$ & $7,1 \pm 0,6$ \\
\hline & \multirow[t]{2}{*}{ painful } & $1 \mathrm{st}$ & $6,4 \pm 1,3$ & $2,9 \pm 0,1$ \\
\hline & & 2nd & $6,7 \pm 0,5$ & $4,5 \pm 1,2$ \\
\hline & \multirow[t]{2}{*}{ unpainful } & $1 \mathrm{st}$ & $3,33 \pm 1,1$ & $2,65 \pm 0,3$ \\
\hline & & 2nd & $2,84 \pm 0,08$ & $1,66 \pm 0,05$ \\
\hline \multirow{2}{*}{\multicolumn{2}{|c|}{ Total running time of }} & $1 \mathrm{st}$ & $42,2 \pm 5,4$ & $23,1 \pm 2,5$ \\
\hline & & 2nd & $36,6 \pm 3,1$ & $34,1 \pm 1,3$ \\
\hline \multicolumn{2}{|l|}{ Painful-to-unpainful } & $1 \mathrm{st}$ & $1,55 \pm 0,07$ & $0,42 \pm 0,02$ \\
\hline ischemic episods ratio & & 2nd & $3,4 \pm 0,1$ & $2,1 \pm 0,2$ \\
\hline \multirow{2}{*}{\multicolumn{2}{|c|}{ Heart rate, mins }} & $1 \mathrm{st}$ & $88,6 \pm 2,0$ & $74,9 \pm 3,1$ \\
\hline & & 2nd & $87,4 \pm 2,1$ & $80,3 \pm 1,4$ \\
\hline \multirow{2}{*}{\multicolumn{2}{|c|}{$\begin{array}{l}\text { Number of taken } \\
\text { nitroglycerin pills, per } \\
\text { week }\end{array}$}} & $1 \mathrm{st}$ & $3,5 \pm 0,2$ & $1,72 \pm 0,1$ \\
\hline & & 2nd & $3,4 \pm 0,17$ & $2,9 \pm 0,15$ \\
\hline
\end{tabular}

Table 4. Results of subjective evaluation of state of health in both groups

\begin{tabular}{lcc}
\hline Parameter & Main group (\%) $\mathrm{n}=27$ & Comparative group (\%) $\mathrm{n}=32$ \\
\hline Weakness & $24(88,88 \%)$ & $27(84,37 \%)$ \\
Undue fatiguability & $21(77,77 \%)$ & $24(75,0 \%)$ \\
Memory impairment & $24(88,88 \%)$ & $30(93,75 \%)$ \\
Attention disorder & $22(81,48 \%)$ & $28(87,50 \%)$ \\
Dizziness & $17(62,96 \%)$ & $27(84,37 \%)$ \\
Syncope & $3(11,11 \%)$ & $0(0 \%)$ \\
Headache & $23(85,18) \%$ & $18(56,25 \%)$ \\
Initial insomnia & $13(48,14 \%)$ & $17(53,12 \%)$ \\
Anxiety & $20(74,07 \%)$ & $21(65,62 \%)$ \\
Soreness & $11(40,74 \%)$ & $19(59,37 \%)$ \\
Inner pressure & $16(59,25 \%)$ & $21(65,62 \%)$ \\
Heart discomfort & $18(66,66 \%)$ & $22(68,75 \%)$ \\
Heartbeats & $22(81,48 \%)$ & $23(71,87 \%)$ \\
Heart malfunction & $19(70,37 \%)$ & $20(62,50 \%)$ \\
Feeling short of breath & $14(51,85 \%)$ & $12(37,5 \%)$ \\
\hline
\end{tabular}

According to our data, histochrome infusions weren't followed by significant changes of general laboratory and biochemical analysis results at the main group patients (table 5). 
Table 5. Dynamics of clinical laboratory and biochemical parameters of patients suffering from acute coronary syndrome with ST-segment depression during the course of histochrome treatment

\begin{tabular}{lcc}
\hline Parameter & $1^{\text {st }}$ day of hospitalization & $10^{\text {th }}$ day of hospitalization \\
\hline Erythrocyte, $\times 1012 /$ liters & $3,70 \pm 0,22$ & $3,08 \pm 0,21$ \\
Hemoglobin, g/l & $134,35 \pm 2,15$ & $132,14 \pm 4,76$ \\
Bilirubin, moles per liter & $12,82 \pm 3,55$ & $12,05 \pm 0,33$ \\
Total cholesterol, moles per liter & $5,23 \pm 0,11$ & $5,13 \pm 1,20$ \\
Glucose, moles per liter & $6,12 \pm 0,32$ & $5,32 \pm 0,22$ \\
Fibrinogen, g/l & $2,36 \pm 0,11$ & $2,55 \pm 0,29$ \\
Prothrombin ratio, $\%$ & $86,53 \pm 2,61$ & $75,12 \pm 3,42$ \\
AST & $21,23 \pm 1,23$ & $19,12 \pm 3,11$ \\
ALT & $34,21 \pm 1,72$ & $32,33 \pm 4,57$ \\
Creatinine & $84,23 \pm 2,64$ & $80,24 \pm 3,18$ \\
\hline
\end{tabular}

According to our questionnaire, evidences of asthenic and vegetative syndromes, and cognitive disorder were registered at most of the patients.

\section{Discussion}

For the moment it is determined that electrophysiological and anatomic inhomogenuity of myocardium become the substrate of uprising and registration of late ventriclar potential, while healthy cardiomyocytes intersperse with ischemic, or necrosis and fibrosis loci. Slow fragment ventricle activity arises in case of break of natural parallel orientation of myocardial fiber and division of viable myocardial locus by connective tissue (Garan, 1988). Appearance of late ventriclar potential in the absence of focal myocardial change can be explained by inhomogenuity of electrophysiological characteristics of myocardium owing to late ventriclar potential, and unequal functional changes of cardiomyocyte in case of acute or chronic ischemia (Stepura, 1997). Besides that, necrosis and fibrosis microloci, arising in cardiac muscle due to recrudescence of long-lasting ischemic heart disease, can become pathogenic substrate of late ventriclar potential (Legkonogov, 1997). Such conditions lead to delay and fragmentation of electric signals, significant spread of depolarization, appearance of late or following ventricular activity (Kurz, 1994, Latfullin, 2011).

According to our sources, late ventricular potential is registered at $30,51 \%$ patients, and mostly in patients who previously had myocardial infarction and acute myocardial infarction with Q wave. Consequently, focal myocardial disease becomes the substrate of arise of late fragment ventricular activity.

Previously demonstrated cardio protective characteristics of histochrome were proved by more significant decrease of late ventricular potential (from $29,63 \%$ to $11,11 \%$ ) at the main group patients rather than in comparative group patients (from $31,25 \%$ to $18,75 \%$ ). Improvement of high resolution ECG results at acute myocardial infarction and hypertensive disease together with state stabilization and histochrome treatment can be explained by ischemic myocardial functional recovery and decrease of inhomogenuity of its electrophysiological characteristics. This effect of histochrome can be explained by the ability of echinuschrome (effecter of the medicament) which plays the role of interceptor of free radicals and neutralize the main initiators of nonenzymatic process of peroxidation of membranous lipid accumulating in tissue ischemic injury zone (Lasukova, 1997).

Significant antioxidant effect of histochrome can be also proved by more significant decrease in nitrates use, improvement of 24-hours ECG monitoring parameters, increase of effort tolerance at the patients of the main group.

It bears mentioning, that histochrome use was accompanied by high patient tolerability. The lack of negative effect of the medicament on biochemical parameters allows recommending it to patients with chronic somatic pathology.

To sum up, inclusion of histochrome (in dose of $100 \mathrm{mg}$ /day during three days) to the complex therapy of acute coronary syndrome with ST-segment depression registered on ECG led to the decrease of clinic symptomatology of the disease and improvement of the life quality of patients and it has no side effects.

\section{Conclusions}

The article gives the evidences of cardio protective and anti-ischemic effectiveness of antioxidant medicament histochrome for patients with acute coronary syndrome with ST-segment depression registered on ECG, as 
follows:

- decrease of electric unsteadiness of myocardium and late ventricular potential registration,

- decrease of the number of anginal attacks, what leads to increase of physical and emotional tolerance of patients, and improves prognoses for acute coronary syndrome patients.

The lack of negative effect of histochrome on biochemical parameters of blood (bilirubin, AST, ALT, creatinine) allows recommending it to patients with chronic somatic pathology.

There has been no necessity of cancellation of histochrome in any of the studied cases.

Obtained results allow recommending the inclusion of histochrome in the complex therapy of patients with acute coronary syndrome with ST-segment depression registered on ECG during anginal attack.

\section{Acknowledgments}

"This work was funded by the subsidy allocated to Kazan Federal University for the state assignment in the sphere of scientific activities".

\section{References}

Garan, H., McGovern, B., Canzanello, V., McCauley, J., Bodvarsson, M., Harrington, J., ... Ruskin J. (1988). The effect of potassium ion depletion on postinfarction canine cardiac arrhythmias. Circulation, 77(3), 696-704. http://dx.doi.org/10.1161/01.CIR.77.3.696

Kurz, R., Ren X., \& Franz M. (1994). Dispersion and delay of electrical restitution in the globally ischemic heart. European Heart, 1\#5(4), 547-554.

Lasukova, T., Uskina, E., \& Afanasiev, S., et al. (1997). The influence of emoxypine and histochromee on the process of lipid peroxygenation and activity of creatine phosphokinase-MB of blood serum at patients suffering from ischemic heart disease in dynamics of coronary artery bypass surgery. Experimental and clinical pharmacology, 60(5), 51-53.

Latfullin, I., \& Kim, Z. (2010). Acute coronary syndrome with ST-segment depression diagnosed on ECG: new approach to the old problem (what do we know and what should we know).

Latfullin, I., Kim, Z., Teptin, G., \& Konturov, S. (2002). Study of late ventricular potentials at patients with unstable angina with ST-segment depression. Cardiovascular therapy and practice, 1(4), 47-53.

Latfullin, I., Kim, Z., Teptin, G., Mamedova, L., \& Khromova, A. (2011). Opportunities of high-resolution electrocardiography in discovering the reasons of ischemic heart diseace instability. Cardiovascular therapy and prevention, 3, 51-57.

Legkonogov, A. (1997). The results and perspectives of late ventricular potentials stusy. Cardiology, 10, 57-65.

Markov, V., Buimov, G., \& Maksimov, I., et al. (1999). the influence of new water-miscible bioantioxidant histochromee on reperfusion injury accompanied by thrombolysis at patients sufferinf from acute myocardial infarction. Cardiology, 12.

Mishenko, N. (1991). All-union conference of quinone and quinone compounds chemistry. Reports theisis. Novosibirsk, p. 164.

Novikov, V., Anufiev, V., \& Levickiy, D., et al. (1996). Pat of USSR\#1822549; Bulletin of inventions\#23, Moscow.

Opie, L. H. (1991). The Heart (2nd ed.). New York, NY. Raven Press.

Richmond, D. R. (1980). Coronary artery spasm: A review. J. Royal Soc. Med., 73, 570-575.

Schamroth, L. (1975). The electrocardiology of coronary artery disease. Blackwell Scientific Publication. Oxford.

Shvilkin, A., Afonskaya, N., \& Cherpachenko, N., et al. (1991). Cardiology, 31(1), 81-82.

Shvilkin, A., Serebryakova, L., \& Zkitishvili, O., et al. (1991). Cardiology, 31(1), 79-81.

Stanley, W. C., Lopaschuk, G. D., Hall, J. L., \& McCormack, J. G. (1997). Regulation of myocardial carbohydrate metabolism under normal and ischemic conditions. Potential for pharmacological interventions, 33, 243-257. Cardiovasc. res. P.

Stepura, O., Ostroumova, O., \& Kurilchenko, I., et al. (1997). Clinical significance of average-signal electrocardiography (materials of European Society of Cardiology congresses \# 17 and 18). Russian 
medical news, 1, 42-45.

Zakirova, A., Ivanova, M., \& Golubyatnikov, V., et al. (1997). Pharmacokinetics and clinical effectiveness of histochromee for patients with acute myocardial infarction. Experimental and clinic pharmacology, 60(6), 21-24.

Zakirova, A., Lebedev, A., \& Kukharchuk, V., et al. (1996). Antioxidant histochromee: influence on lipid peroxygenation and blood rheological properties at unstable angina patients. Therapeutic archives., 68(8), 12-15.

\section{Copyrights}

Copyright for this article is retained by the author(s), with first publication rights granted to the journal.

This is an open-access article distributed under the terms and conditions of the Creative Commons Attribution license (http://creativecommons.org/licenses/by/3.0/). 